\title{
Effects of topographic variability on the scaling of plant species richness in gradient dominated landscapes
}

Post-print/Accepted manuscript

Gabriela Hofer

Helene H. Wagner

Felix Herzog

Peter J. Edwards

Hofer, G., Wagner, H. H., Herzog, F. and Edwards, P. J. (2008), Effects of topographic variability on the scaling of plant species richness in gradient dominated landscapes. Ecography, 31: 131-139. doi:10.1111/j.2007.0906-7590.05246.x

This is the peer reviewed version of the following article: Hofer, G., Wagner, H. H., Herzog, F. and Edwards, P. J. (2008), Effects of topographic variability on the scaling of plant species richness in gradient dominated landscapes. Ecography, 31: 131-139, which has been published in final form at doi:10.1111/j.2007.09067590.05246.x This article may be used for non-commercial purposes in accordance with Wiley Terms and Conditions for Self-Archiving.

\section{HOW TO CITE TSPACE ITEMS}

Always cite the published version, so the author(s) will receive recognition through services that track citation counts, e.g. Scopus. If you need to cite the page number of the TSpace version (original manuscript or accepted manuscript) because you cannot access the published version, then cite the TSpace version in addition to the published version using the permanent URI (handle) found on the record page. 
1 Effects of topographic variability on the scaling of plant species richness in

2 gradient dominated landscapes

3 Gabriela Hofer ${ }^{1}$, Helene H Wagner $^{2}$, Felix Herzog ${ }^{1}$ Peter J Edwards ${ }^{3}$

4

51 FAL Agroscope Reckenholz, Swiss Federal Research Station for Agroecology and Agricul-

6 ture, Zürich, Switzerland, gabriela.hofer@art.admin.ch and felix.herzog@art.admin.ch

72 WSL, Swiss Federal Research Station for Forest, Snow and Landscape, 8903 Birmensdorf,

8 Switzerland, helene.wagner@wsl.ch

93 Institute of Integrative Biology (IBZ), Swiss Federal Institute of Technology, ETH, Univer-

10 sitätsstrasse 16, 8092 Zurich, Switzerland, edwards@env.ethz.ch

11 
12

\section{Abstract}

The variation of abiotic and biotic site conditions is often associated with the variation of niches, which in turn is hypothesised to constrain species richness of an area. Based on theoretical considerations, abiotic variation is often used as an estimator of species richness at broad scales, while the variation of habitats is used at finer landscape scales. However, habitat estimators imply a discrete, patchy structure of the landscape with homogenous patches and sharp boundaries, which does not apply well in gradient dominated landscapes. The aim of this study was therefore to investigate effects of abiotic heterogeneity at a finer landscape scale on plant species richness and their $(\alpha)$ and beta $(\beta)$ components at microsite, habitat and local landscape level. For 12 landscapes of $1 \mathrm{~km}^{2}$ the effects of two simple and one complex measures of topographic variability on species richness components were analysed and compared by linear regression models. Species richness of landscapes was explained to a high extent by the standard deviation (SD) of altitude $\left(\mathrm{R}^{2}=0.63\right)$, but the complex measure, SD of solar radiation, explained it even better $\left(\mathrm{R}^{2}=0.82\right)$. The $\beta$ diversity components increased as expected significantly with topographic variability of local landscapes. There was, however, an additional context effect of landscape heterogeneity on $\alpha$ diversity components at microsite level, indicating a shift of mean microsite conditions. Further analyses revealed that the effects of topographic variability on species richness originated mainly from grassland, although woody habitats also had an influence. The effects of abiotic variability on landscape species richness and their diversity components suggest that - even at a fine landscape scale the underlying abiotic pattern cannot be neglected if we are to understand patterns of species richness and the processes that maintain them.

\section{Keywords}


Environmental heterogeneity, topographic variability, species richness, meso scale, local landscapes, additive partitioning, alpha and beta species richness components.

\section{Introduction}

Biodiversity of an area (gamma diversity) is composed of the diversity at sites ( $\alpha$ component) and the heterogeneity between sites ( $\beta$ component) (Whittaker 1977, Allan 1975). As local diversity is spatially limited, gamma diversity is expected to be strongly dependent on the heterogeneity between sites (Plotkin \& Müller-Landau 2002). In contrast to mean ecological conditions, ecological heterogeneity is associated with the variance of niches in an area and has therefore been hypothesized to be an important driver of species richness at broad and fine scales (Palmer \& Dixon 1990, Plotkin \& Müller-Landau 2002). While the heterogeneity of abiotic parameters is often included in modelling to account for variance in species richness at broad scales (Richerson \& Lum 1980, Currie 1991, Riera et al. 1998, Gaston 2000, Coblentz \& Riitters 2004), the heterogeneity of discrete patches e.g. habitats, land cover or land use are mainly included to predict variance in species richness at landscape scale (Moser et al. 2002, Benton et al. 2003) which corresponds to the meso scale in the spatio-temporal hierarchy of Delcourt \& Delcourt (1988). This reflects theoretical considerations saying that climate and topography deliver the abiotic envelope for the occurrence of species at broad scales, while their realized occurrence is thought to be determined at meso and micro scales by biotic interactions, land-use pattern, disturbance and succession (Cornell \& Lawton 1992, Klijn \& DeHaes 1994). Based on the biodiversity concept of Whittaker (1977) and Allan (1975) habitat heterogeneity is expected to be an appropriate correlate of species richness in landscapes with a simple, two dimensional patch mosaic structure with low variation within habitats and discrete borders among habitats. However, in topographically heterogeneous landscapes those two basic criteria are only partly met. Steep abiotic gradients cause gradual shifts in species 
compositions within and between habitats (McGarigal \& Cushman 2005) which makes the delineation of homogenous patches conceptionally unsatisfying and hardly reproducible in practice. However, the topographic relief of a landscape has a strong impact on abiotic microsite conditions (Swanson et al.1988), which in turn affect vegetation patterns (Larcher 1973, Ellenberg 1986, Franklin 1995) as well as land use patterns (Dorner et al. 2002, Wrbka et al. 2004). Consequently, we hypothesized that variability of topography is not only an appropriate surrogate of niche diversity and estimator of species richness at broad scales as currently used, but also at landscape scale. It remains an open question how to quantify topographic variability so as to maximize correlation with plant species diversity.

Most studies which integrated topographic variability used the SD of altitude (e.g. Richerson \& Lum 1980, Currie 1989, Moser et al. 2005, Pausas et al. 2003, Luoto et al. 2002), some authors used the SD of slope (Coblentz \& Riitters 2004) or other measures like for example the SD of curvature (Wrbka et al. 2004), all derived from digital elevation models (DEM). While the aspect is well known to be relevant for the occurring vegetation type (e.g. Bale et al. 1998, Benayas et al. 1999, Ortega et al. 2004, Sebastia 2004), these measures of topographic variability ignore the variability of aspect. Variability measures which integrate aspect are therefore expected to explain species richness pattern better. Franklin et al. (2000) called variables which combine topographic and direct or resource variables (e.g. solar radiation or wetness) 'complex topographic variables' and showed that they explain vegetation pattern in general better than simple topographic variables. In the present study, we therefore compared two established, simple measures of topographic variability (SD of altitude and SD of slope) with a complex topographic variable (SD of the potential yearly solar radiation), expecting that the complex variable integrating aspect is a better measure of abiotic variability. 
The surface area of a landscape increases as a function of topographic variability. This collinearity caused confusion in numerous studies investigating heterogeneity effects because it could not be separated from a simple surface area effect (Forman 1995). After the suggestion of Whittaker et al. (1998) this problem is avoided by the assessment of an equal number of samples of a comparable total area within study units of different topographic variability. Biotic heterogeneity between sites can then be assessed by the partitioning of species richness data in $\alpha$ and $\beta$ species richness components (Whittaker 1977, Allan 1975, Lande 1996, Wagner et al. 2000, Crist et al. 2003), expecting an increase of the $\beta$ (heterogeneity) components with topographic heterogeneity. Lande et al. (1996) extended the additive diversity approach of Allan (1975) and demonstrated how several scale levels of diversity can be linked in an ecological system with commensurate $\alpha$ and $\beta$ diversity components. This is an advantage compared to the multiplicative approach of Whittaker (1977) where $\alpha$ and $\beta$ components have different units and are therefore not comparable. Additive partitioning allows to investigate and compare diversity at several scale levels coevally - one of the important claims of the hierarchy theory (O’Neill 1986) to assess the context and explaining details for the phenomenon of interest. As in mountainous areas topographic variability often increases with altitude, a problematic collinearity is also expected between altitude and its variability, and climatic heterogeneity might be a potentially confounding parameter for variance in species richness. One way to investigate microsite variability independently of climatic variability or broad scale shifts in species pools along altitudinal gradients is to define an environmentally homogenous study area where a common species pool is assumed.

The ecological interpretation of total species richness (gamma diversity) of a landscape requires not only the integration of hierarchical levels and the calculation of $\alpha$ and $\beta$ components but also the distinction of species richness in different habitats (Zobel 1997). While e.g. 
grassland species richness increases with decreasing nutrient values in the soil, the richness of

110 woody species is expected to be higher at nutrient rich sites (Cornwell \& Grubb 2003), and

111 this example demonstrates that even constant species richness might cover contrary dynamics.

112 Especially in improved agricultural landscapes, edges are known to be refugies for species

113 sensitive to intensification (Smart 2002) and this is why in addition to the present habitats,

114 species richness in edges might be important to understand the distribution of species richness

115 in a landscape.

117 This meso scale study investigates the effect of topographic variability on plant species rich-

118 ness in local landscapes in the Swiss pre-Alps. To exclude potential confounding effects

119 caused by shifts in species pool, we choose a climatically and biogeographically homogenous

120 study area. To avoid confounded variables of species richness and area we assessed a stand-

121 ardized sample of 40 plant species relevées within 12 study units of $1 \mathrm{~km}^{2}$ each. The research questions are parted in one main and three sub questions:

123 Is topographic variability an effective estimator of species richness at landscape scale?

124

a) How to quantify topographic variability so as to maximize correlation with plant species diversity?

b) Which species diversity components increase with topographic variability?

c) Does the influence of topography vary between habitat types?

\section{Methods}

\section{Study area}

The study area was a mountainous region in Canton Lucerne, Switzerland, covering $250 \mathrm{~km}^{2}$ within the "montane” altitudinal belt (600 to 1000 meters above sea level). Land cover is pre- 
132 dominantly shared by agriculture, mostly grassland (53\%) and forest (37\%). The mean annual

133 precipitation is between 1500 and $1800 \mathrm{~mm} / \mathrm{m}^{2}$ and the mean annual temperature $11.3^{\circ} \mathrm{C}$.

\section{Sampling of local landscapes}

135 All topographic variables used in this study were derived from a digital elevation model 136 (DEM) (Swisstopo 2001) with a resolution of $25 \mathrm{~m}$. Starting with a 1-km grid, three components of Topographic Variability (TV) were calculated for each of the 250 cells: SD of altitude $\left(\mathrm{TV}_{\mathrm{SDALT}}\right)$, $\mathrm{SD}$ of slope $\left(\mathrm{TV}_{\mathrm{SDSLOP}}\right)$, and $\mathrm{SD}$ of potential annual solar radiation

139 ( $\left.T V_{\text {SDRAD }}\right)$, a measure including the variability of orientation). The potential sum of 140 shortwave solar radiation per year (short: radiation) was calculated with "DiGem" (Conrad 141 2002) based on the DEM. We assumed an atmospheric transmittance of 60 percent (standard 142 of DiGem), and the variable was estimated based on calculations every 15 days with time 143 steps of two hours. The three components of topographic variability were standardized by 144 constraining the observed range between zero and one (Sneath and Sokal 1973).

145 The sum of the three components $\left(\mathrm{TV}_{\mathrm{SUM}}\right)$ was used to derive a stratified sample of the 250

146 cells. To do this we ranked the cells and grouped them into septiles; three $1-\mathrm{km}^{2}$ cells were 147 then sampled randomly from the first, third, fifth and seventh septile, yielding a sample of 12 148 local landscapes. With this stratification, we were sure to cover the whole range of topograph149 ic variability in the study area. Because of our focus was on agricultural landscapes, cells with 150 less than 40 percent of open landscape were excluded.

\section{Sampling within the local landscapes}

152 Sampling was based on stratification by habitat class and topography, with the aim of maxim153 izing variability of vegetation types and species composition among sampling units. Habitat 154 classes were digitized from true-colour ortho-photographs with a resolution of $0.5 \mathrm{~m}$, and the 155 data were analysed using ARCGIS, version 8.3. All elements of at least two meters width and 
$156100 \mathrm{~m}^{2}$ area were digitized as polygons. A simple habitat classification with ten classes was 157 applied (Table 1). The class "Urban, buildings, settlement” was excluded, and forest was only 158 included in the edge class. The nine remaining habitat classes were aggregated into three habi159 tat types: grassland/arable land, woody and edges (Table 1).

To quantify topographic site conditions, a total of seven topographic variables were extracted

162 from the DEM - four local site variables (altitude, slope, radiation and curvature) and three variables to characterize the context (SD of altitude, slope and radiation within a window of five by five cells of $25 \mathrm{~m}$ ). On the basis of k-means, these topographic variables were clustered for each local landscape into four groups per habitat type.

The four classes of topographic site conditions were crossed with the nine habitat classes, and one point was sampled for each combination (Tab. 1). Because grassland was the dominating

168 habitat class, the sampling effort for grassland was increased and two relevées were made for each combination of grassland with the topographical clusters. Because there was only one arable field in the whole investigation area, the habitat type "grassland/arable" consisted exclusively of grasslands or orchards except for this one sample. We therefore call this group

172 furthermore "grassland habitat". If a specific combination of habitat class and topographic 173 cluster did not occur within a local landscape, an alternative point was drawn randomly within 174 the same habitat class, ignoring the topographical cluster class. If this failed, a point was 175 drawn randomly within the same habitat type.

176 Forty plant species relevées of $25 \mathrm{~m}^{2}$ were recorded within each of the 12 local landscapes to 177 assess species richness components. The shape of the relevées was adapted to the habitat type: 178 "grassland/arable" was sampled using $5 \mathrm{~m}$ by $5 \mathrm{~m}$ squares, while the linear habitats "edge” 179 and "woody" were sampled using 1 m by 25 m rectangles. 


\section{Numerical analyses}

181

182

183

184

185

186

187

188

189

190

191

192

193

194

195

196

197

198

199

200

201

Effect of topographic variability on landscape species richness

The effect of topographic parameters on total observed species richness within the 12 local landscapes was analyzed with multiple linear regression. To select the model with the highest likelihood, we compared the explanatory power of the mean $\left(\mathrm{T}_{\mathrm{M}}\right)$ and the SD of the topographic parameters. The model selection criterion of Akaike for small sample sizes AICc was used, giving advantage to models with few parameters (Burnham \& Anderson 1998). Variables with a Pearson correlation coefficient $r \geq 0.6$ were avoided within the same model. Another aim of this selection process was to choose the most appropriate model for investigating the effect of topographic variability on species richness components.

\section{Additive components of species richness}

We estimated $\alpha$ and $\beta$ components of species richness using the approach of additive partitioning first suggested by Allan (1975) and further developed by Lande (1996). As suggested by Lande (1996), Wagner et al. (2000) and Crist et al. (2003), three scale levels - microsite, habitat and landscape - were linked within each of the 12 local landscapes. For level i, an $\alpha$ component is calculated by the average species number within the pooled samples at level $\mathrm{i}$.

The $\beta$ component of level i results from the difference between $\alpha_{i}$ and $\alpha_{i+1}$ :

Landscape (12)

$\alpha_{3}$ (= gamma diversity)

Habitat type (3 x 12)

$\alpha_{2}+\beta_{2}$

Plot $(40 \times 12)$

$\alpha_{1}+\beta_{1}$

\section{Effect of topographic variability on species richness components}


The effect of topographic variability on each species richness component was assessed with a

203 linear regression on $\mathrm{TV}_{\text {SDRAD}}$, based on the best fitting model from the previous analysis. 204 Normality of the residuals was tested with Shapiro Wilk's test for normal distribution; in ad205 dition, we checked the random distribution of the residuals with a scatter plot of predicted 206 versus residual values.

\section{Results}

208 We recorded a total of 413 plant species in 480 samples $\left(25 \mathrm{~m}^{2}\right)$ distributed within 12 local 209 landscapes. The number of species recorded in individual local landscapes ranged from 161 to $210 \quad 208$.

\section{Quantification of topographic variability}

212 The correlation matrix (Tab. 2) shows the Pearson correlation coefficients of the six variables 213 which were thought to be included in the model selection procedure. However, as slope was 214 correlated with all the variability variables it was omitted, because it would not have been 215 possible to separate heterogeneity effects from effects of mean conditions. Combinations and 216 subsets of the four remaining topographic variables were included in the model selection pro217 cedure if they did not reach an $r \geq 0.6$.

In the model selection procedure, the highest likelihood (which is lowest AICc) was reached

220 by a regression model with one single variable, TV SDRAD. After the rule of thumb of Burnham 221 and Anderson (1998), further candidate models are those with an AICc value differing from 222 the best model by less than two; in our case only one model, with TV $\mathrm{SDRAD}_{\text {and }} \mathrm{T}_{\text {MRAD }}$, met 223 this criterion. In addition to the two candidate models that were identified, Table 3 summariz224 es for purposes of comparison the regression models including only one of the four topo- 
225

graphic variables. For $\mathrm{TV}_{\mathrm{SDRAD}}$, the $\mathrm{R}^{2}(0.82)$ was substantially higher than for the next best single variables $\mathrm{T}_{\mathrm{MSLOP}}(0.64)$ and $\mathrm{TV}_{\mathrm{SDRAD}}(0.60)$. $\mathrm{TV}_{\mathrm{SDRAD}}$ was therefore used as a surrogate for topographic variability in subsequent analyses. The best model without the variable $\mathrm{TV}_{\mathrm{SDRAD}}$ had an $\mathrm{R}^{2}$ of 0.72 and AICc rank five.

\section{Effect of topographic variability on plant diversity components}

The linear regressions for the different species richness components are shown in Figure 1 for the whole landscape and in Figure 2 for the three habitat types separately. For the whole landscape, partitioning into variability $(\alpha)$ and heterogeneity $(\beta)$ components at three levels showed that all components increased with topographic variability. At the microsite level, topographic variability explained comparable amounts of $\alpha$ and $\beta$ components $\left(\mathrm{R}^{2}\right.$ of 0.78 and 0.80 respectively), while at the level of habitat type, topographic variability explained more of the $\alpha$ component than of the $\beta$ component ( $\mathrm{R}^{2}$ of 0.82 and 0.47 respectively).

The separate calculation of species richness components for each habitat type revealed consistent strong effects of topographic variability on all diversity components of the "grassland" habitat type, with $\mathrm{R}^{2}$ between 0.79 and 0.88 . The species richness in the habitat type “edges” was consistently higher than in the other habitat types, but the components of species richness were unaffected by topographic variability . In contrast, the species richness components of the "woody" habitat type were significantly affected by topographic variability on the $\beta_{1}\left(\mathrm{R}^{2}=\right.$ $0.29)$ and $\alpha_{2}\left(R^{2}=0.36\right)$ level, but with comparably low $R^{2}$. There was no effect of topographic variability on the $\alpha_{1}$ level.

\section{Discussion}




\section{Topographic variability is an effective landscape-scale estimator of species richness}

249 The high amount of variance in plant species richness explained by topographic variability supported the hypotheses that those measures are not only efficient estimators at macro and broad meso scales (sensu Delcourt \& Delcourt 1988) but also at a finer meso scale such as the local landscapes of $1 \mathrm{~km}^{2}$ in this study. It is important to recognize that the effects of topographic variability differed from the effects of the mean conditions for altitude and radiation because those parameters varied independently. Two studies at the border of meso to macro scale (sensu Delcourt \& Delcourt) derived contradicting results concerning the importance of topographic heterogeneity. While Pausas et al. (2003, extent: $31900 \mathrm{~km}^{2}$, grain size: 10 by 10 $\mathrm{km}^{2}$ ) estimated topographic heterogeneity as significant for species richness but not distinguishable from the confounded increase of area, Moser et al. (2005, extent: $50500 \mathrm{~km}^{2}$, grain size: 6 by $6 \mathrm{~km}^{2}$ ) found that topographic heterogeneity was not important at the scale of their study. Several reasons might be responsible for these conflicting results, because besides of the probably real differences, the quality of the species richness data might be different, different measures of topographic heterogeneity were used and the model selection procedure was not the same. It might therefore be easier to derive the reasons for the consistently detected effects at finer meso scale: The present study and Luoto (2002) cover both a climatically homogenous area and are therefore able to exclude important climate induced shifts in the presence of species and habitats which are expected to be confounded with heterogeneity. Although there are certainly additional parameters influencing species richness in local landscapes the strong effects of topographic variability indicates the significant impact of the abi-

269 otic envelope on local processes (microsite conditions, land use) and challenges the common notion of the environmental envelope being relevant only at broader scales. 
273 Studies in grasslands and in forests have shown the importance of aspect for biodiversity, 274 vegetation types and species composition (e.g. Miller \& Franklin 2002, Bale et al. 2004, Se275 bastia et al. 2004). We therefore explain the best fit of the linear regression model based on $276 \mathrm{TV}_{\mathrm{SDRAD}}\left(\mathrm{R}^{2}=0.82\right)$ as due to the additional information about the variability of aspect; this 277 information that is not represented in the parameters slope or altitude. Our results confirm the 278 findings of Franklin et al. (2000) that in explaining the distribution of plant species complex topographic parameters that are linked to resource or direct environmental variables (sensu Austin and Smith 1989) have more predictive power than simple topographic variables. The best model without $T V_{\text {SDRAD }}$ included both $\mathrm{T}_{\text {MALT }}$ and $\mathrm{TV}_{\text {SDALT }}\left(\mathrm{R}^{2}=0.72\right)$, suggesting that by including the variability of the orientation to the sun, there was at least a $10 \%$ gain in variance explained. Nevertheless, also the simple regression model including $\operatorname{TV}_{\text {SDALT }}\left(\mathrm{R}^{2}=0.63\right)$ as predictor was able to explain species richness to a considerable degree.

\section{Alpha and beta diversity components contribute both to the landscape species richness}

The additive partitioning of landscape species richness in $\alpha$ and $\beta$ components at the microsite and habitat level revealed two important points. First, the expected and confirmed significant increase of $\beta$ diversity (heterogeneity) between microsites with increasing topographic variability was a strong support for the heterogeneity hypotheses and excluded a simple species area effect like described by Forman (1995). Secondly, $\alpha$ components increased significantly with increasing topographic variability, too, and therefore the heterogeneity components were not exclusively responsible for an increase of landscape species richness with topographic variability. The phenomenon of the context or matrix landscape affecting local $\alpha$ diversity has been found before in patch mosaic landscapes (e.g. Dauber et al. 2003, Aviron et al. 2005, Gabriel et al. 2005), showing that the share of certain habitats in the surrounding affects diversity at sites. The hypothesis of these studies are based on the meta population theory, ex- 
pecting a higher rate of immigration with a higher share of habitat in the context, leading to more saturated local communities (species pool effect, Hanski \& Gaggiotti 2004). Kumar et al. (2006) found effects of context patch heterogeneity on local $\alpha$ diversity (species richness) while in the present study, we found effects of context topographic heterogeneity on local species richness for a gradient dominated landscape, where biotic heterogeneity should not be estimated by patch heterogeneity (Cushman \& Mc Garigal 2005). In addition to meta population effects, other processes are expected to contribute the significant increase of microsite species richness with topographic landscape variability. In the present study, the topographic variability of the context is expected to affect accessibility for land use and might cause less intensive, biodiversity promoting land use practices with increasing topographic variability. Abiotic site conditions were not only more variable in landscapes of higher topographic variability like indicated by the $\beta$ species richness components, but the increase in $\alpha$ diversity components suggests in addition an ecological shift of the mean microsite conditions. The increase of $\alpha$ diversity components with topographic variability in the investigated local landscapes could be an effect of either an increasing local species pool or decreasing management intensity. Although we did not investigate these causes in the present study, the strength of the effect suggests that the underlying topographic pattern in our study area governs the most important patterns determining species richness.

\section{The effect of topographic variability depends on the habitat type}

The separate analysis of the diversity components within the three habitat types grassland, edges and woody is an important step to better understand the effect of topographic variability. Topographic variability did not affect all habitat types equally (Figure 2a-c): Total species

321 richness within habitat types $\left(\alpha_{2}\right)$ increased strongest in grassland but also in woody habitats, while edges made no contribution to this effect. As we know from earlier studies, topography 
affects species composition of various grassland types (e.g. Sebastia et al. 2004, Benayas et al. 1999) and woody habitats (Bale et al. 1998, Ortega et al. 2004). The fact that the $\beta$ components at the microsite level increased in both the grassland and woody habitat types is therefore not surprising and suggests that differences in species composition among microsites tended to be greater in landscapes with high topographic variability; this is presumably due to higher microsite variability in such landscapes. However, grassland and woody habitats dif-

329 fered in the behaviour of the $\alpha 1$ components at the microsite level. Grassland species richness tends to be higher at nutrient poor sites, both wet and dry, than at nutrient rich sites (Cornwell \& Grubb 2003). These favorable site conditions for biodiversity are more likely to occur on steeper slopes which are naturally less fertile, though they may also persist in flat areas that are not intensified because of poor accessibility. The $\alpha_{1}$ microsite components of woody habitat types did not increase with topographic variability which might indicate that for woody habitats, heterogeneity components were almost exclusively contributing to the increase of total species richness with topographic variability.

Several reasons may explain higher species richness in edges compared to grassland and woody habitat types: 1) edges may contain species from two contiguous habitats (Zonneveld 1995), 2) they are known to provide residual habitats for plant species that have otherwise been lost from intensively managed agricultural landscapes (Smart 2002), and 3) a high variability in site conditions can be expected in edges because of the contrasting influences of adjacent habitats (e.g. wet, dry, shady). The effects 2) and 3) would both cause a higher relative

344 contribution of edges to observed total species richness $\left(\alpha_{3}\right)$ in topographically homogeneous 345 and more intensively managed landscapes than in landscapes with higher environmental variability and would lead to the observed results. 


\section{Conclusions}

349 Abiotic heterogeneity explained high amounts of landscape species richness. This contradicts

350 the common notion that abiotic parameters are estimators of broad meso and macro species

351 richness patterns while patch heterogeneity is needed to explain species richness at finer

352 scales. While an increase of $\beta$ diversity components was expected with abiotic variability re-

353 flecting the increase of niche variability, the additional effects of landscape level heterogenei-

354 ty at microsite level indicate that the abiotic heterogeneity of the context affected local micro-

355 site conditions. The results show, that even at finer meso scale, the underlying pattern of to-

356 pography cannot be neglected if we are to understand patterns of species richness and the pro-

357 cesses that maintain them.

358

\section{Acknowledgements}

360 The authors are very grateful to I. Kump for field work, Bob Bunce for useful advice about

361 the design and field work, the Swiss Federal Office for the Environment (FOEN) for species 362 richness data, the GIS Coordination Office of the Canton Lucerne for the free use of the true363 color ortho-photographs and the Management Office of the Biosphere Entlebuch for support.

\section{References}

365 Allan J.D. (1975). Components of Diversity. Oecologia 18, 359-367.

366 Austin M.P. \& Smith T.M. (1989). A new model for the continuum concept. Vegetatio 83: 3547.

368 Aviron S., Burel F., Baudry J. \& Schermann N. (2005). Carabid Assemblages in Agricultural 
Landscapes: Impacts of Habitat Features, Landscape Context at Different Spatial Scales and Farming Intensity. Agriculture Ecosystems \& Environment 108, 205-217.

Bale C.L., Williams J.B. \& Charley J.L. (1998). The Impact of Aspect on Forest Structure and Floristics in Some Eastern Australian Sites. Forest Ecol Manag 110, 363-377.

Benayas J.M.R., Colomer M.G.S. \& Levassor C. (1999). Effects of Area, Environmental Status and Environmental Variation on Species Richness Per Unit Area in Mediterranean Wetlands. J Veg Sci 10, 275-280.

Benton T.G., Vickery J.A. \& Wilson J.D. (2003). Farmland Biodiversity: Is Habitat Heterogeneity the Key? Trends Ecol Evol 18, 182-188.

Burnham K.P. \& Anderson D.R. (1998). Model Selection and Inference: A Practical InformationTheoretic Approach. Springer-Verlag.

Coblentz D.D. \& Riitters K.H. (2004). Topographic Controls on the Regional-Scale Biodiversity of the South-Western Usa. J Biogeogr 31, 1125-1138.

Conrad O. (2002). URL http://www.geogr.uni-goettingen.de/pg/saga/digem/index.html

Cornell H.V. \& Lawton J.H. (1992). Species Interactions, Local and Regional Processes, and Limits to the Richness of Ecological Communities - a Theoretical Perspective. J Anim Ecol 61, 1-12.

Cornwell W.K. \& Grubb P.J. (2003). Regional and Local Patterns in Plant Species Richness With Respect to Resource Availability. Oikos 100, 417-428.

Crist T.O., Veech J.A., Gering J.C. \& Summerville K.S. (2003). Partitioning Species Diversity Across Landscapes and Regions: a Hierarchical Analysis of Alpha, Beta, and Gamma 
392

393

394

395

396

397

398

399

400

401

402

403

404

405

406

407

408

409

410

411

Currie D.J. (1991). Energy and Large-Scale Patterns of Animal-Species and Plant-Species Richness. Am Nat 137, 27-49.

Dauber J., Hirsch M., Simmering D., Waldhardt R., Otte A. \& Wolters V. (2003). Landscape Structure as an Indicator of Biodiversity: Matrix Effects on Species Richness. Agriculture Ecosystems \& Environment 98, 321-329.

Delcourt, H. and Delcourt, P. 1988. Quaternary landscape. ecology: relevant scales in space and time. Landsc. Ecol. 2:. 23-44.Dorner B., Lertzman K. \& Fall J. (2002). Landscape Pattern in Topographically Complex Landscapes: Issues and Techniques for Analysis. Landscape Ecol 17, 729-743.

Dorner B., Lertzman K. \& Fall J. (2002). Landscape Pattern in Topographically Complex Landscapes: Issues and Techniques for Analysis. Landscape Ecology 17, 729-743.

Ellenberg H. (1996). Vegetation Mitteleuropas mit den Alpen in ökologischer, dynamischer und historischer Sicht. 5. stark veränderte und verbesserte. Auflage, Stuttgart, Ulmer.

Forman R.T.T. (1995). Land mosaics: the ecology of landscapes and regions. Cambridge University Press, Cambridge, UK.

Franklin J. (1995). Predictive Vegetation Mapping: Geographic Modelling of Biospatial Patterns in Relation to Environmental Gradients. Prog Phys Geog 19, 474-499.

Franklin J., McCullough P., Gray C. (2000). Terrain variables used for predictive mapping of vegetation communities in southern California. In: Wilson J., Gallant J. (Eds.), Terrain analyses: Principles and Applications. 331-353. 
412 Gabriel D., Thies C. \& Tscharntke T. (2005). Local Diversity of Arable Weeds Increases 413 With Landscape Complexity. Perspectives in Plant Ecology Evolution and Systematics 7, $414 \quad 85-93$

Gaston K.J. (2000). Global Patterns in Biodiversity. Nature 405, 220-227.

416

417

418

Gottfried M., Pauli H. \& Grabherr G. (1998). Prediction of Vegetation Patterns at the Limits of Plant Life: a New View of the Alpine-Nival Ecotone. Arctic and Alpine Research 30, 207-221.

Hanski I.A., Gaggiotti O.E. (2004). Ecology, Genetics and Evolution of Metapopulations: Standard Methods for Inventory and Monitoring. Elsevier Academic Press, London.

Klijn F. \& De Haes H.A.U. (1994). A Hierarchical Approach to Ecosystems and Its Implications for Ecological Land Classification. Landscape Ecol 9, 89-104.

Kumar S., Stohlgren T.J. \& Chong G.W. (2006). Spatial Heterogeneity Influences Native and Nonnative Plant Species Richness. Ecology 87, 3186-3199.

Lande R. (1996). Statistics and Partitioning of Species Diversity, and Similarity Among Multiple Communities. Oikos 76, 5-13.

Larcher W. (2001). Ökophysiologie der Pflanzen: Leben, Leistung und Stressbewältigung der Pflanzen in ihrer Umwelt. 6. neu bearbeitete Auflage, Stuttgart, Ulmer.

Luoto M., Toivonen T. \& Heikkinen R.K. (2002). Prediction of Total and Rare Plant Species Richness in Agricultural Landscapes From Satellite Images and Topographic Data. Landscape Ecol 17, 195-217.

McGarigal, K., and S. Cushman. 2005. The gradient concept of landscape structure. Pages 
112-119 in J. Wiens and M. Moss, eds. Issues and Perspectives in Landscape Ecology. Cambridge University Press, Cambridge.

435

436

437

438

439

440

441

442

443

444

445

446

447

448

449

450

451

452

453

454

Miller J. \& Franklin J. (2002). Modeling the Distribution of Four Vegetation Alliances Using Generalized Linear Models and Classification Trees With Spatial Dependence. Ecol Model $157,227-247$.

Moser D., Zechmeister H.G., Plutzar C., Sauberer N., Wrbka T. \& Grabherr G. (2002). Landscape Patch Shape Complexity as an Effective Measure for Plant Species Richness in Rural Landscapes. Landscape Ecol 17, 657-669.

Moser D., Dullinger S., Englisch T., Niklfeld H., Plutzar C., Sauberer N., Zechmeister H.G. \& Grabherr G. (2005). Environmental Determinants of Vascular Plant Species Richness in the Austrian Alps. J Biogeogr 32, 1117-1127.

O’Neill R.V., DeAngelis D.L., Waide J.B., Allan T.F.H. (1986). A Hierarchical Concept of Ecosystems. Princeton University Press, Princeton, New Jersey.

Ortega M., Elena-Rosello R. \& Del Barrio J.M.G. (2004). Estimation of Plant Diversity at Landscape Level: a Methodological Approach Applied to Three Spanish Rural Areas. Environ Monit and Assess 95, 97-116.

Palmer M.W. \& Dixon P.M. (1990). Small-Scale Environmental Heterogeneity and the Analysis of Species Distributions Along Gradients. J Veg Sci 1, 57-65.

Pausas J.G., Carreras J., Ferre A. \& Font X. (2003). Coarse-Scale Plant Species Richness in Relation to Environmental Heterogeneity. J Veg Sci 14, 661-668.

Plotkin J.B. \& Muller-Landau H.C. (2002). Sampling the Species Composition of a Landscape. Ecology 83, 3344-3356. 
455

Richerson P.J. \& Lum K. (1980). Patterns of Plant-Species Diversity in California - Relation to Weather and Topography. Am Nat 116, 504-536.

Riera J.L., Magnuson J.T., Castle J.R.V. \& Mackenzie M.D. (1998). Analysis of Large-Scale Spatial Heterogeneity in Vegetation Indices Among North American Landscapes. Ecosystems 1, 268-282.

Sebastia M.T. (2004). Role of Topography and Soils in Grassland Structuring at the Landscape and Community Scales. Basic Appl Ecol 5, 331-346.

Smart S.M., Bunce R.G.H., Firbank L.G. \& Coward P. (2002). Do Field Boundaries Act as Refugia for Grassland Plant Species Diversity in Intensively Managed Agricultural Landscapes in Britain? Agr Ecosyst Environ 91, 73-87.

Sneath P.H.A. \& Sokal R.R. (1973). Numerical taxonomy - The principles and practice of numerical classification. W.H. Freemann, San Francisco.

Swanson F.J., Kratz T.K., Caine N. \& Woodmansee R.G. (1988). Landform Effects on Ecosystem Patterns and Processes. Bioscience 38, 92-98.

Swisstopo (2001)., DHM25: Das digitale Höhenmodell der Schweiz. Bundesamt für Landestopographie.

Wagner H.H., Wildi O. \& Ewald K.C. (2000). Additive Partitioning of Plant Species Diversity in an Agricultural Mosaic Landscape. Landscape Ecol 15, 219-227.

Whittaker R.H. (1977). Evolution of species diversity in land communities. In Evolutionary Biology. Vol. 10, 1-67. Edited by Hecht M.K. \& Steere B.W.N.C.. Plenum Press, New York.

Whittaker R.J. (1998). Island Biogeography. Ecology, Evolution and Conservation. Oxford 
478 Whittaker, R.J., Willis, K.J. \& Field, R. (2001). Scale and species richness: towards a general 479 hierarchical theory of species diversity. J. Biogeogr., 28, 453-470.

480 Wiens J.A.(1989). Spatial scaling in ecology. Funct Ecol 3: 385-397.

481 Wrbka T., Erb K.H., Schulz N.B., Peterseil J., Hahn C. \& Haberl H. (2004). Linking Pattern and Pro482 cess in Cultural Landscapes. An Empirical Study Based on Spatially Explicit Indicators. Land Use $483 \quad$ Policy 21, 289-306.

484 Zobel M. (1997). The Relative Role of Species Pools in Determining Plant Species Richness: An Al485 ternative Explanation of Species Coexistence? Trends Ecol Evol 12, 266-269.

486 Zonneveld I.S. (1995). Vicinism and Mass Effect. J Veg Sci 6, 441-444. 
487 Table 1: Stratification matrix for the sampling within each of the 12 local landscapes of 1

$488 \mathrm{~km}^{2}$ : Nine habitat classes were combined with four classes of topography. In total, 40 points

489 were sampled randomly within each local landscape (36 points plus 4 grassland points extra).

490 The numbers of samples is indicated in the four columns of the matrix.

491

\begin{tabular}{|l|l|l|l|l|l|}
\hline Habitat types & Habitat classes & \multicolumn{4}{|c|}{$\begin{array}{c}\text { Topographic } \\
\text { Clusters }\end{array}$} \\
\hline \multirow{4}{*}{$\begin{array}{l}\text { Grassland and arable } \\
\text { habitats }\end{array}$} & 1 Grassland & 1 & 2 & \multicolumn{2}{|c|}{$\mathbf{4}$} \\
\cline { 2 - 7 } & 2 Orchards & 2 & 2 & 2 & 2 \\
\cline { 2 - 7 } & 3 Arable land & 1 & 1 & 1 & 1 \\
\hline \multirow{5}{*}{ Edge habitats } & 4 Roads/tracks/paths & 1 & 1 & 1 & 1 \\
\cline { 2 - 7 } & 5 Waters & 1 & 1 & 1 & 1 \\
\cline { 2 - 7 } & 6 Forest edge & 1 & 1 & 1 & 1 \\
\hline \multirow{3}{*}{ Woody habitats } & 7 Hedgerow & 1 & 1 & 1 & 1 \\
\cline { 2 - 7 } & 8 Riparian Woods & 1 & 1 & 1 & 1 \\
\cline { 2 - 7 } & $\begin{array}{l}\text { 9 Other Groups of Bush- } \\
\text { es/Trees }\end{array}$ & 1 & 1 & 1 & 1 \\
\hline Rest & 10 Buildings, Settlements & & & & 1 \\
\hline
\end{tabular}

492 
493 Table 2: Pearson's correlation coefficients (r) of the investigated explaining topographic var494 iables. Bold printed are significantly correlating $\mathrm{r}$ coefficients with $\mathrm{p}<0.05$. The topographic 495 parameters were abbreviated as following: Prefix T stands for topographic parameter and pre496 fix TV for topographic variability. Inferior abbreviations: mean = M, standard deviation $=\mathrm{SD}$, 497 altitude $=$ ALT; slope $=$ SLOP; radiation $=$ RAD.

498

\begin{tabular}{|l|c|c|c|c|c|c|}
\hline & $T_{\text {MALT }}$ & $T_{\text {MSLO }}$ & $T_{\text {MRAD }}$ & TV $_{\text {SDALT }}$ & TV $_{\text {SDSLOP }}$ & TV $_{\text {SDRAD }}$ \\
\hline $\mathbf{T}_{\text {MALT }}$ & 1.00 & & & & & \\
\hline $\mathbf{T}_{\text {MSLO }}$ & 0.47 & 1.00 & & & & \\
\hline $\mathbf{T}_{\text {MRAD }}$ & -0.10 & -0.27 & 1.00 & & & \\
\hline TV $_{\text {SDALT }}$ & 0.07 & $\mathbf{0 . 8 1}$ & -0.36 & 1.00 & & \\
\hline TV & -0.16 & $\mathbf{0 . 6 7}$ & -0.48 & $\mathbf{0 . 7 8}$ & 1.00 & \\
\hline TV & 0.49 & $\mathbf{0 . 9 5}$ & -0.32 & $\mathbf{0 . 7 8}$ & $\mathbf{0 . 6 5}$ & 1.00 \\
\hline
\end{tabular}

499 
500 Table 3: Selected regression models explaining observed total species richness of the 12 local

501 landscapes of $1-\mathrm{km}^{2}$ are shown ranked by Akaike’s criterion for small sample sizes (AICc

502 rank). For abbreviations of included variables see Table 2.

\begin{tabular}{|l|l|c|c|c|c|c|c|}
\hline $\begin{array}{c}\text { AICc } \\
\text { rank }\end{array}$ & \multicolumn{1}{|c|}{$\begin{array}{c}\text { Variables } \\
\text { included }\end{array}$} & $\begin{array}{c}\text { Multiple } \\
\mathbf{R}\end{array}$ & $\begin{array}{c}\text { Multiple } \\
\text { Rsquares }\end{array}$ & $\begin{array}{c}\text { Adjusted } \\
\text { Rsquares }\end{array}$ & $\begin{array}{c}\mathbf{F ( 1 , 1 0 ) /} \\
\mathbf{F ( 2 , 9 )}\end{array}$ & $\mathbf{p}$ & $\begin{array}{c}\text { Std. } \\
\text { Error }\end{array}$ \\
\hline 1 & $\mathrm{TV}_{\mathrm{SDRAD}}$ & 0.91 & 0.83 & 0.82 & 49.56 & 0.0000 & 7.34 \\
\hline 2 & $\mathrm{TV}_{\mathrm{SDRAD}} / \mathrm{T}_{\mathrm{MRAD}}$ & 0.92 & 0.84 & 0.80 & 23.48 & 0.0003 & 7.57 \\
\hline 7 & $\mathrm{TV}_{\mathrm{SDALT}}$ & 0.80 & 0.63 & 0.60 & 17.24 & 0.0020 & 10.85 \\
\hline 9 & $\mathrm{~T}_{\mathrm{MALT}}$ & 0.42 & 0.18 & 0.09 & 2.14 & 0.1741 & 16.25 \\
\hline 10 & $\mathrm{~T}_{\mathrm{MRAD}}$ & 0.37 & 0.14 & 0.05 & 1.63 & 0.2303 & 16.60 \\
\hline
\end{tabular}




\section{Figure legends:}

505

506 Figure 1: Effects of topographic variability - measured as standard deviation of solar radia507 tion - on species richness components at microsite level $\left(\alpha_{1}, \beta_{1}\right)$, habitat type level $\left(\alpha_{2}, \beta_{2}\right)$ and 508 landscape level $\left(\alpha_{3}\right)$. Simple linear regressions were performed based on all 40 plant species 509 relevées within a local landscape of $1 \mathrm{~km}^{2} .(*=\mathrm{p}<0.05, * *=\mathrm{p}<0.01, * * *=\mathrm{p}<0.001)$

511 Figure 2: Effect of topographic variability - measured as standard deviation of solar radiation

512 - on species richness components within habitat types on microsite level $\left(\alpha_{1}, \beta_{1}\right)$ and habitat 513 type level $\left(\alpha_{2}\right)$. Simple linear regressions were performed within the three habitat types 514 “grassland”, “edge” and "woody” separately. (* $\left.{ }^{*} \mathrm{p}<0.05, * *=\mathrm{p}<0.01, * * *=\mathrm{p}<0.001\right)$ 


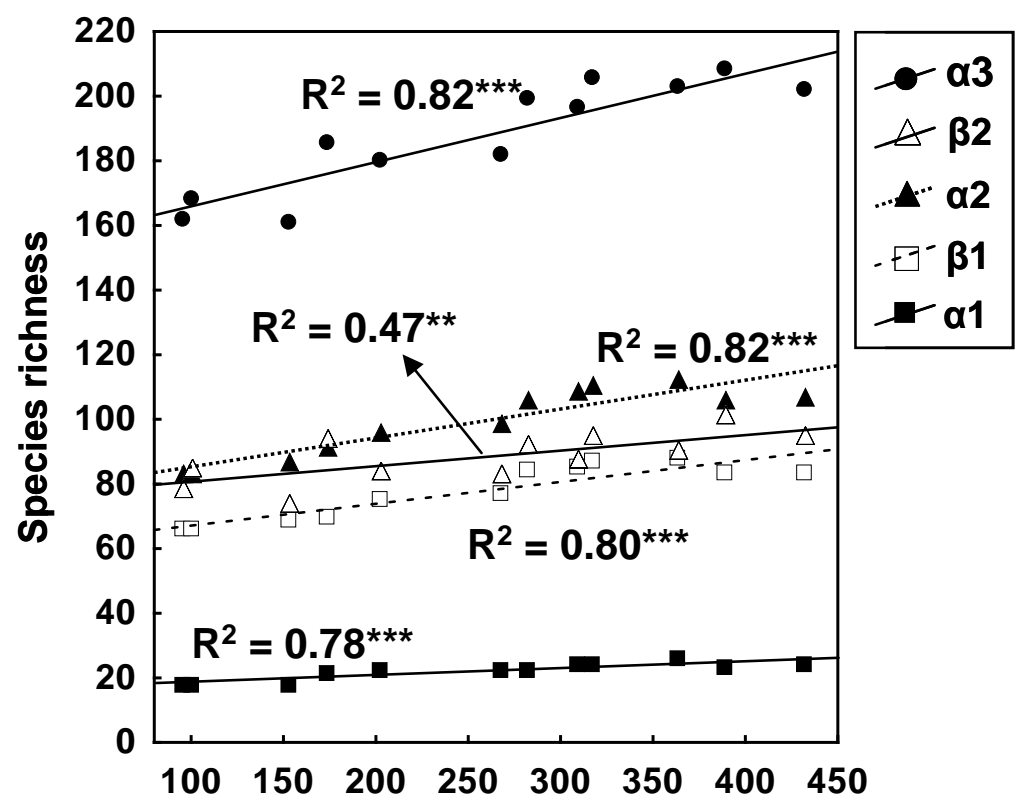

Standard deviation of solar radiation

516 Hofer, Wagner, Herzog \& Edwards

$517 \quad$ Figure 1

518

519 

a) Grassland/arable land b) Edge habitats
c) Woody habitats

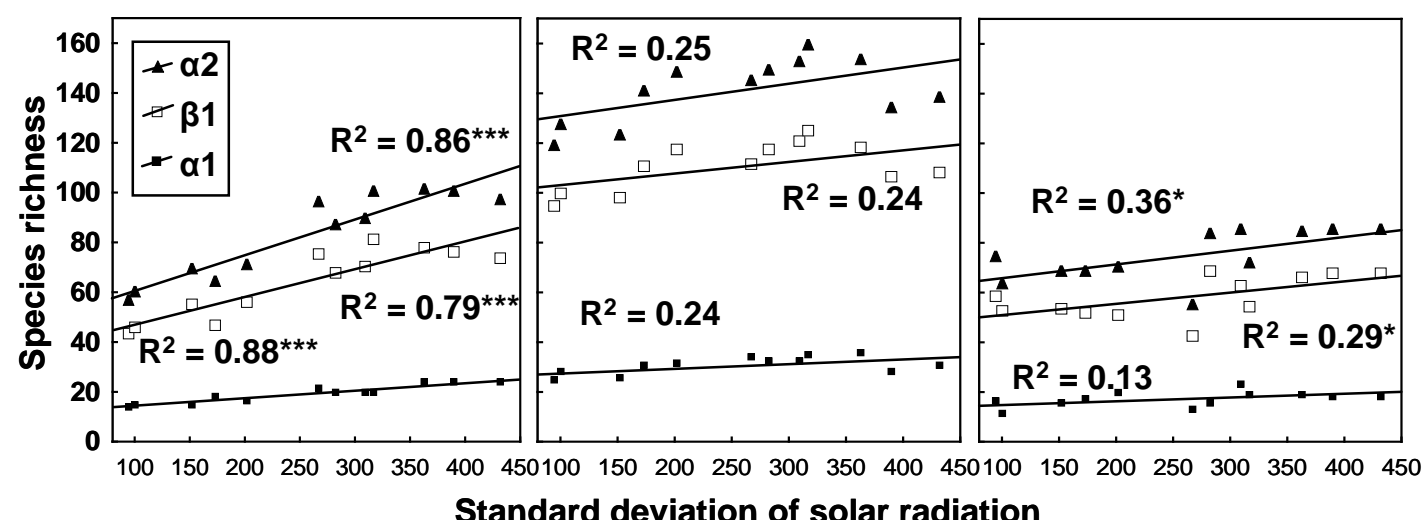

521

\section{Standard deviation of solar radiation}

522 Hofer, Wagner, Herzog \& Edwards

523 Figure 2 